\title{
Proposing a Novel Economical and Reversible Method for Hydrogen Production Using Solar Oven
}

\author{
Vahid Mirzaei Mahmoud Abadi ${ }^{1, ~ *}$, Amirkhosro Beheshti ${ }^{2}$, Mohsen Mirhabibi ${ }^{3}$, \\ Mohammad Bagher Askari ${ }^{3}$, Shila Banari Bahnamiri ${ }^{4}$ \\ ${ }^{1}$ Faculty of Physics, Shahid Bahonar University of Kerman, Kerman, Iran \\ ${ }^{2}$ Department of Chemistry, Payame Noor University, Tehran, Iran \\ ${ }^{3}$ Department of Physics, Payame Noor University, Tehran, Iran \\ ${ }^{4}$ Vocational School Girls, Vocational University of Babol, Babol, Iran
}

Email address:

Vah_mirzaei@uk.ac.ir(V.M. M. Abadi)

${ }^{*}$ Corresponding author

\section{To cite this article:}

Vahid Mirzaei Mahmoud Abadi, Amirkhosro Beheshti, Mohsen Mirhabibi, Mohammad Bagher Askari, Shila Banari Bahnamiri. Proposing a Novel Economical and Reversible Method for Hydrogen Production Using Solar Oven. Journal of Energy and Natural Resources. Vol. 6, No. 6, 2017, pp. 69-72. doi: 10.11648/j.jenr.20170606.11

Received: December 6, 2017; Accepted: December 25, 2017; Published: January 18, 2018

\begin{abstract}
Hydrogen production is an effective step toward using clean energies and an appropriate substitution for fossil fuels. One of the very important concerns in the field of renewable energy is the conversion of the latent energies into electrical energy that could be carried out by developing hydrogen fuel cells as the cheap and also stable electrocatalysts for hydrogen evolution process. In the present work, some new methods of hydrogen production will be introduced after enumerating the advantages and disadvantages of hydrogen fuel and the global approach rate toward this clean fuel. Finally, a new method will be presented based on a chemical, economical, green and reproducible reaction through aqueous solution by means of solar ovens for hydrogen production.
\end{abstract}

Keywords: Hydrogen, Solar Oven, Solar Energy, Clean Energies, Fossil Fuel

\section{Introduction}

Energy is one of the ten main challenges of humans' future [1]. Clean energies is one the vast and important fields globally considered due to several reasons; Hydrogen production and its numerous applications as a fuel has recently been critically considered by experts and the technology to produce, reserve, and transfer hydrogen is among the effective steps considered by research centers including Atomic Energy Organization in order to utilize hydrogen as a replace for fossil fuels [2] [3]. The features distinguishing hydrogen from other fuel choices include: abundance, almost unique consumption, ignorable amount of pollution, reversibility, and low greenhouse effects. Using hydrogen along with fuel cells points out a promising future [4]. Due to its independency from primary sources of energy, hydrogen energy system is a perpetual, sustainable, inclusive, and renewable system. It is predicted that hydrogen production and consumption as an energy carrier will spread all over the global economy, and hydrogen economy will be stabilized [5-7]. The main issue about hydrogen is its production. There are several methods studied in different articles, some of which being efficient but expensive [8]. Bing based on hydrogen production through some chemical reactions by means of one or two intermediates and one consumable substance, one of the new methods recently introduced is KHAMIS method, in which a nuclear reactor supplies the energy of chemical reactions. In this method, a considerable cycle is sulfur-lode (S-I) cycle known as (Ispra Mark 16) which was first introduced in the US by General Atomics and then developed by different institutes like Japan Atomic Energy Agency (JAEA). In fact, this cycle is composed of three chemical reactions in which in $900^{\circ} \mathrm{C}$ reaction (1):

$$
\mathrm{H}_{2} \mathrm{SO}_{4} \rightarrow 1 / 2 \mathrm{O}_{2}+\mathrm{SO}_{2}+\mathrm{H}_{2} \mathrm{O}
$$


Then in $400^{\circ} \mathrm{C}$ reaction (2) occurred:

$$
2 \mathrm{HI} \rightarrow \mathrm{H}_{2}+\mathrm{I}_{2}
$$

The output of these two reactions is divided into two groups: the first group is output products exit from the cycle and used, including oxygen and hydrogen, whereas the second group is the very chemical intermediates mentioned above returned to the cycle. In other words, $\mathrm{SO}_{2}, \mathrm{H}_{2} \mathrm{O}$ and $\mathrm{I}_{2}$ are the intermediates that will be added to the cycle again. After that, the cycle is added to the intermediate compounds of water and the initial compounds of reaction (1) and (2) will be obtained. Therefore, the chemical cycle is continued.

From all thermal cycles, the S-I cycle is the most efficient. The theoretical value of the efficiency for total process with the assumption of ideal reversible chemical reactions is evaluated as 51\%. Analytical studies predict the efficiency to be between $40 \%$ and $50 \%$. The result of the analysis in 1982 by General Atomics has evaluated the thermal efficiency of this process to be $47 \%$. The general scheme of S-I cycle is shown in Figure 2 [9].

Hydrogen can be produced using diverse, domestic resources-including fossil fuels, such as natural gas and coal (with carbon sequestration); nuclear energy; and other renewable energy sources, such as biomass, wind, solar, geothermal, and hydro-electric power-using a wide range of processes.

Hydrogen can be produced:

At or near the site of use in distributed production

At large facilities and then delivered to the point of use in central production

At intermediate scale facilities located in close proximity (25-100 miles) to the point of use in semi-central production.

The overall challenge to hydrogen production is cost. For cost-competitive transportation, a key driver for energy independence, hydrogen must be comparable to conventional fuels and technologies on a per-mile basis. In order for fuel cell electric vehicles to be competitive, the total untaxed, delivered and dispensed, cost of hydrogen needs to be less than $\$ 4 /$ gge. A gge, or gasoline gallon equivalent, is the amount of fuel that has the same amount of energy as a gallon of gasoline. One kilogram of hydrogen is equivalent to one gallon of gasoline.

Today, hydrogen storage systems for transportation are as follows [10]:

1. storage in the form of compressed gas in steel and composite tanks

2. storage in the form of liquid in supercool tanks

3. storage in metallic hydrides

The main advantage of using hydrogen as fuel is the output after combustion, which is steam, water, and nitrogen oxide [11]. Other advantages of using hydrogen are:

- Its ease of transfer through piping

- The heat produced by the combustion per unit weight is more than that of other fuels

- Is considered as a general fuel because its combination with air to combust in a wide band is changeable

- Its remains in an enclosed area can be cleared by airflow; its toxicity is less than other fuels

- Hydrogen is environmentally harmless [12]

Problems in using hydrogen energy:

- Quickly changes from liquid to gas in normal temperature

- Needs high pressure in liquid mode to keep in a storage

- Is highly permeable

- Quickly combines with oxygen

- Needs to decrease its temperature up to $-253^{\circ} \mathrm{C}$ to liquefy in which its density is too low

- Its thermal energy is $32 \%$ of thermal value of methane gas (about $3070 \mathrm{Kcal} / \mathrm{m}^{3}$ ) [13]

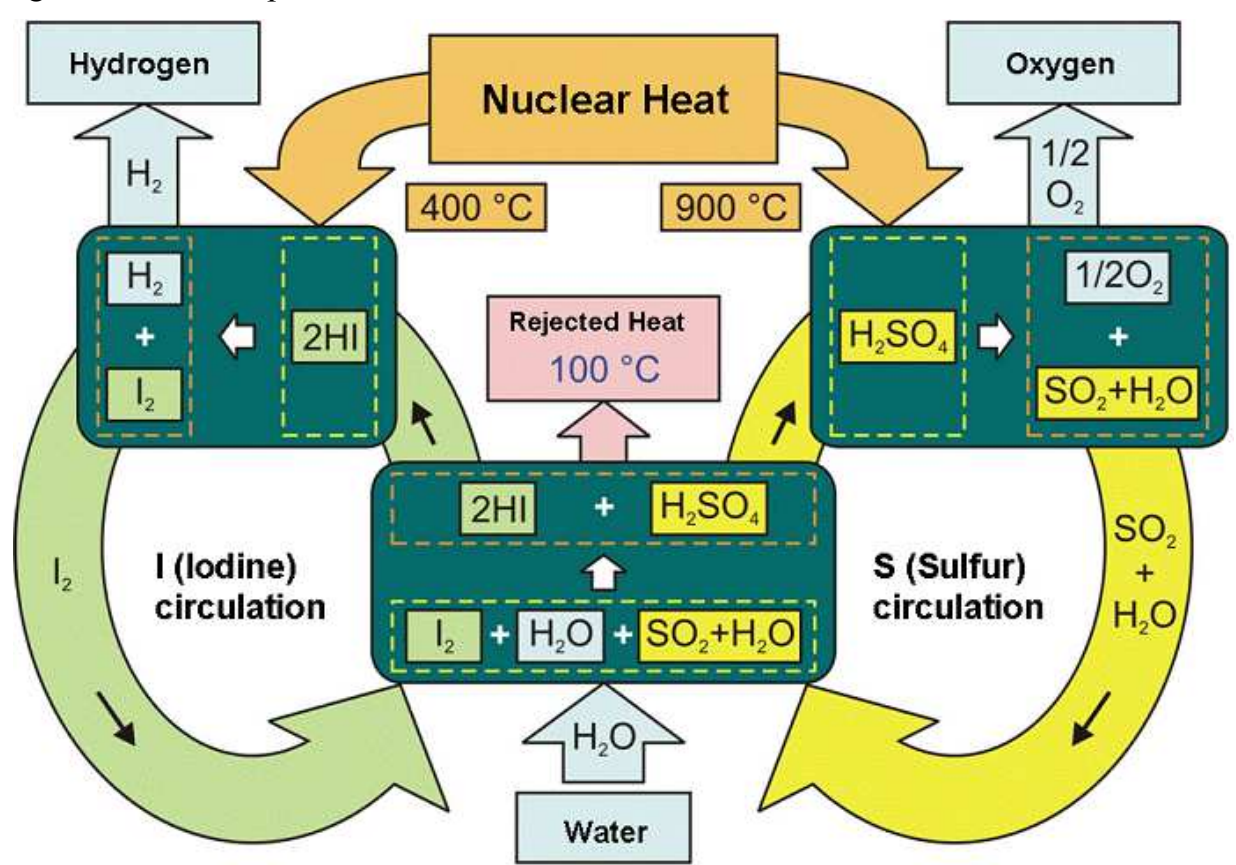

Figure 1. General scheme of S-I thermal cycle for water splitting. 


\section{Hydrogen Production by Solar Energy}

The sun is always considered by different countries of the world as the most available source of energy [14]. The present research team used solar ovens to supply the temperature required for chemical reactions. In this phase, we exactly explained the structure of hydrogen producer and its reversible chemical processes after briefly studying and elaborating solar ovens function.

\section{Solar Oven}

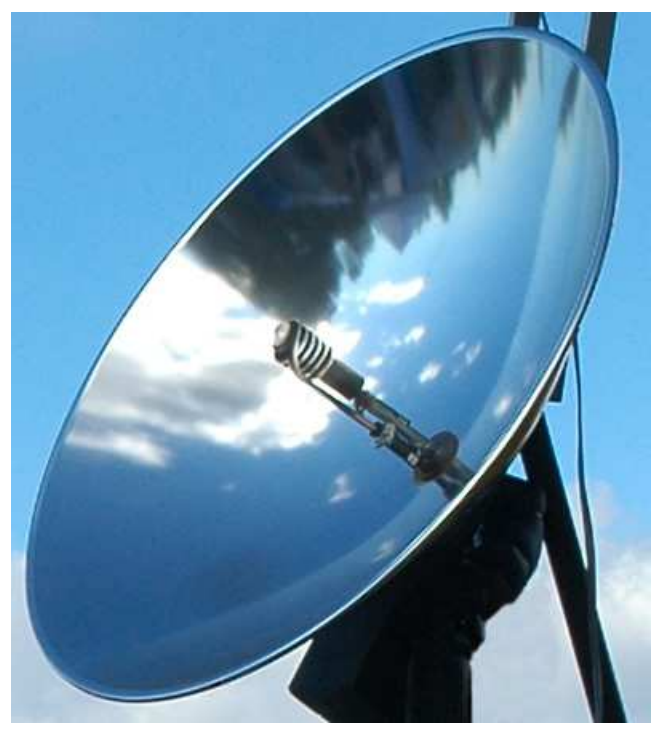

Figure 2. Dish-like solar oven.

Solar oven is a device to produce heat through concentrating the sunlight in a specific spot. The solar oven is in the form of concave plate, covered by mirror to reflect the sunlight. Two common solar ovens are shown in the following images. Image 2 is a dish-like oven and image 3 is a parabolic oven which is the most common oven working with two mirrors: flat and concave. The sunlight is shown to the flat mirror and is then reflected toward the concave one. According to the optics principles, when a set of parallel beams of light shine to a concave mirror, the beams concentrate on the focal point of the mirror. Therefore, the sunlight beams are concentrated in the focal point of the concave mirror and raise its temperature. One of the main advantages of solar ovens is their producing pure heat without any pollution [15].

\section{The Proposed New Method}

An economical and energy-saving method for hydrogen production can be achieved through solving aluminum in an alkaline intermediate (Process 3) (AlHidroc process); a disadvantage of this method is application of $\mathrm{NaOH}$ solution that can be corrosive. Using sodium aluminum hydride or sodium alanate $\left(\mathrm{NaAlH}_{4}\right)$ is recommended in the present research. Major advantages of this method are: energy saving, capability to be designed as a light and compact system, and, most importantly, its reproduction of the initial material. Hydrogen is produced during two steps in this process: first, in normal temperature $\left(50-70^{\circ} \mathrm{C}\right)$ and with titanium nanoparticles as catalyzer, the sodium aluminum hydride changes into metallic aluminum and hydrogen gas $\left(\mathrm{Na}_{3} \mathrm{AlH}_{6}\right)$ and then $\mathrm{Na}_{3} \mathrm{AlH}_{6}$ produces hydrogen again in $250^{\circ} \mathrm{C}$. The required heat in this process is supplied by a solar oven. As seen in the equations, 1.5 mole hydrogen gas is produced from each mole of sodium aluminum hydride. Aluminum is one of byproducts of the first step that can reproduce the initial material through hydrolyze process (Equation 4) [16].

$$
3 \mathrm{NaAlH}_{4} \stackrel{\text { Heat, }(2-5 \mathrm{Wt} \% \mathrm{Ti})}{\longrightarrow} \mathrm{Na}_{3} \mathrm{AlH}_{6}+3 \mathrm{H}_{2}+2 \mathrm{Al} \stackrel{250^{\circ} \mathrm{C}}{\longrightarrow} 3 \mathrm{NaH}+3 / 2 \mathrm{H}_{2}
$$

$2 \mathrm{NaAlH}_{4}+3 / 2 \mathrm{O}_{2} \rightarrow 2 \mathrm{NaH}+2 \mathrm{Al}+3 \mathrm{H}_{2} \mathrm{O}$

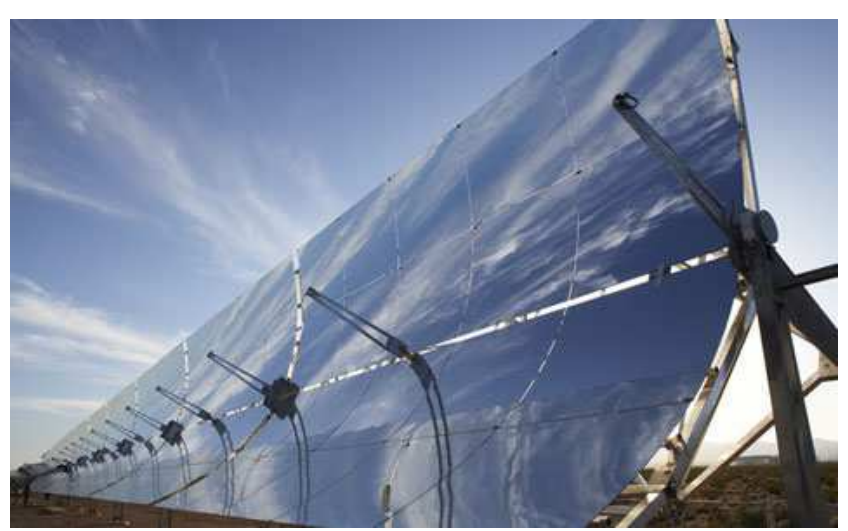

Figure 3. Parabolic solar oven.

Figure 4 is the diagram of the proposed new method.

\section{Results and Discussion}

Hydrogen production in different parts of the world is being increasingly considered in recent years, owing to countries changing policies from using fossil fuels to clean ones. Hydrogen production is industrially of concerns in the countries tending to use hydrogen technology. Several methods for hydrogen production were reviewed in the present paper, including profitable and economical methods that most countries apply. Inspired by Khamis article, this research tried to propose a device similar to Khamis for hydrogen production with advantages more than those of Khamis. In other words, rather than using a nuclear reaction as Khamis does, our proposed method uses solar oven in order to supply the heat for the process. 


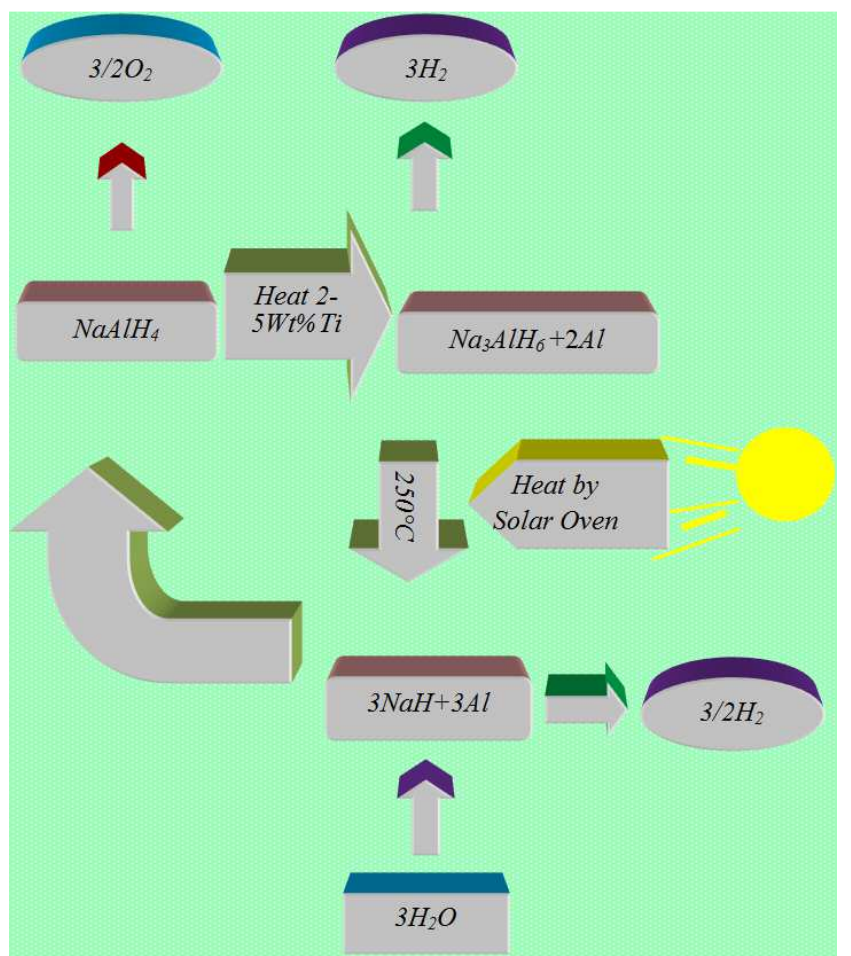

Figure 4. Hydrogen production by solar oven through a reversible chemical process.

Of course, using the solar energy is more available and safer than a nuclear process, in addition to the clearly lower cost of using a solar oven than producing heat by a nuclear reaction. The second advantage of this proposed device is the lower heat required than by Khamis; in other words, maximum temperature required for our proposed device is $250^{\circ} \mathrm{C}$, whereas it is $900^{\circ} \mathrm{C}$ in Khamis. Briefly, besides numerous ways of hydrogen production currently used all over the world, the present research tried to propose designing and manufacturing a novel device with a reversible and economical process compatible with environment through using the solar energy.

\section{Conclusion}

Because of the importance of energy crisis and growing human need to the energy, it has become one of the most important challenge around the world. As we know hydrogen can be a clean and accessible source of energy. producing and preservation of hydrogen are two major subjects in this field. Naturally the price of hydrogen producing is important. In this study it has been tried to introduce a new affordable method for producing hydrogen. within the introduced cyclic process at low temperature and by solar energy, this method is affordable. The authors believe that the suggested method has a high potential for practical use in economical and green hydrogen production

\section{References}

[1] Bahrampour, Mohammad Reza, et al. "The consideration of Lut desert potential in the production of electric energy from solar energy." World Journal of Engineering 13.3 (2016): 275-280.

[2] Navarro, R. M., M. A. Pena, and J. L. G. Fierro. "Hydrogen production reactions from carbon feedstocks: fossil fuels and biomass." Chemical reviews 107.10 (2007): 3952-3991.

[3] Veziroğlu, T. Nejat, and Sümer Şahi. "21st Century's energy: Hydrogen energy system." Energy conversion and management 49.7 (2008): 1820-1831.

[4] Jacobson, M. Z., W. G. Colella, and D. M. Golden. "Cleaning the air and improving health with hydrogen fuel-cell vehicles." Science 308.5730 (2005): 1901-1905.

[5] Suzuki T, Iwanami HI, YoshinariT. Steam reforming of kerosene on $\mathrm{Ru} / \mathrm{Al}_{2} \mathrm{O}_{3}$ catalyst. Int J Hydrogen Energy 2000; 25: 119e26.

[6] Yang RX, Chuang KH, Wey MY. Hydrogen production through methanol steam reforming: effect of synthesis parameters on $\mathrm{Ni}-\mathrm{Cu} / \mathrm{CaO}-\mathrm{SiO}_{2}$ catalysts activity. Int $\mathrm{J}$ Hydrogen Energy 2014; 39: 19494e501.

[7] Oar-Arteta L, Remiro A, Aguayo AT, Bilbao J, Gayubo AG. Effect of operating conditions on dimethyl ether steam reforming over a $\mathrm{CuFe}_{2} \mathrm{O}_{4} / \mathrm{g}-\mathrm{Al}_{2} \mathrm{O}_{3}$ bifunctional catalyst. Ind Eng Chem Res 2015; 54: 9722e32.

[8] Greeley J, Jaramillo TF, Bonde J, Chorkendorff I, Norskov JK. Computational high throughput screening of electrocatalytic materials for hydrogen evolution. Nat Mater 2006; 5: 909e13.

[9] KHAMIS, I., "The development of hydrogen economic evaluation programmeme (HEEP)" (Proc. 4th OECD/NEA Information Exchange Meeting on Nuclear Hydrogen Production, Oakbrook, 2009) OECD-NEA Report No. 6805, Paris (2010) 281-287.

[10] Tan, Zhaosheng, and Michael A. Fetcenko. "Hydrogen storage system." U.S. Patent No. 7,651,554. 26 Jan. 2010.

[11] Akansu, S. Orhan, et al. "Internal combustion engines fueled by natural gas - hydrogen mixtures." International Journal of Hydrogen Energy 29.14 (2004): 1527-1539.

[12] http://www.fuelcelltoday.com/about-fuel-cells/benefits.

[13] http://www.conserve-energy future.com/Advantages_Disadvantages_HydrogenEnergy. php.

[14] Mohsen, Mirhabibi, et al. "Comparing the generation of electricity from renewable and non-renewable energy sources in Iran and the world: now and future." World Journal of Engineering 12.6 (2015): 627-638.

[15] Carter, Albert. "Solar oven." U.S. Patent No. 811, 274. 30 Jan. 1906.

[16] Jorge Macanás, Lluís Soler, Angélica María Candela, Maria Muñoz, Juan Casado, Hydrogen generation by aluminum corrosion in aqueous alkaline solutions of inorganic promoters: The AlHidrox process, Energy 36 (2011) 2493-2501. 